\title{
Surgical.
}

\section{THE USE AND ABUSE OF PLASTER OF PARIS.}

BY B. WHITCHURCH HOWELL, F.R.c.s.

THE occasional application of plaster of Paris may be dangerous to the patient and $\frac{\bar{\Phi}}{\Omega}$ damaging to professional reputations.

Therefore, since the uses of plaster of Paris are many, it behoves the surgeon to $\vec{\circ}$ have completely mastered the technique of its application and the indications for its use.

The use of plaster of Paris may be divided into the following categories :-

I. Immobilization of Limbs.

Use of Plaster of Paris.

(I) Prevention of pain : e.g., in anterior poliomyelitis.

(2) Fractures : e.g., hip, tibia and fibula.

(3) Post-operative : e.g., arthrodesis of wrist, hip, knee.

(4) Arthritis, especially tubercle.

II. Correction of Deformities.

(I) Anterior poliomyelitis.

(2) Arthritis, especially multiple.

(3) Congenital : e.g., club foot.

(4) Scoliosis.

III. Casts.

(I) Spinal supports.

(2) Deformed limbs requiring leather or celluloid splints and supports.

(3) Plaster beds.

(4) Permanent records.

Abuse of Plaster of Paris.

(I) Risk to circulation : e.g., gangrene; Volkmann's ischæmic paralysis.

(2) Risk of sepsis.

(3) Risk of further deformity.

(4) Risk of new deformity.

It will thus be seen that the knowledge of the use of plaster of Paris is essentia for the practice of orthopædic surgery.

(r) Prevention of Pain.

\section{1.--Immobilization of Limb.}

The writer has had considerable experience in the immediate treatment of acuta anterior poliomyelitis by the use of plaster of Paris.

The patient often complains of acute pain in the muscles affected by the paralysiso If these muscles be at once immobilized in the correct and most useful position fore ultimate function, the pain will disappear as if by a miracle, and the limb will slowly recover from its paralysis with no residual deformities. The temperature in manyo instances immediately falls and the patient has sleep. All four limbs may have to be्e treated in this fashion. 


\section{(2) Fractures.}

It is absolutely essential that cases of fracture through the neck of the femur should be treated by complete immobilization in extreme abduction and some internal rotation. In such a case the plaster should extend from the umbilicus down to the foot on the affected side, and as far as the knee on the unaffected side. The plaster should be put on under an anæsthetic on a special orthopædic operation table, such as designed by the writer, and should remain on or be renewed from time to time for a period up to six months, after which a walking calliper should be worn.

Many simple cases of fracture of the lower limb can be reduced and immobilized in plaster of Paris on this special orthopædic operation table. The patient is then able to walk within a few hours or days of the original accident. If much œdema be present then the plaster should be split or bivalved immediately after the reduction of the fracture. This allows for any further swelling, and can be reinforced later by a plaster of Paris bandage round the two halves.

\section{(3) Post-operative.}

For the complete immobilization after an operation to secure ankylosis of bone or joints in a new or most useful position, plaster of Paris is the best method to adopt. For example, an arthrodesis of the wrist can be completely immobilized without pain if plaster of Paris be applied immediately after the operation. Naturally it is essential that a window be cut for the dressing of the wound. After excision of the knee-joint for tuberculous or other disease, it is also useful to apply a Thomas's knee-splint with a simple band of plaster of Paris round the knee-joint. This secures absolute stability without pain, and allows the necessary X-ray films to be taken after the operation.

\section{(4) Arthritis.}

To obtain complete immobility with freedom from pain, plaster of Paris is the perfect medium. This applies in particular to diseases of joints, for example tubercle. It is of course understood that any deformity that may have been present has been previously corrected by extension, manipulation, etc. The plaster is renewed from time to time to avoid as far as possible atrophy of the $\operatorname{limb}$. This is to a certain extent unavoidable, and the small amount that may take place is well compensated for by the excellent function that ensues with its use, whether it be in the treatment of arthritis, fractures, or paralysis.

\section{(I) Anterior Poliomyelitis.}

\section{II.-Correction of Deformities.}

Should deformities develop as a sequel to poliomyelitis they should be corrected by coaxing, by gradual means, preferably by means of plaster of Paris. For example, a case of talipes equino.varus with no deformity of bone can be completely corrected by slowly and gradually stretching the tight structures with the hand or Thomas's wrench, and the correction maintained by the application of plaster. In certain instances, for example with the Thomas's wrench, an anæsthetic is necessary, but in the majority such corrections are obtained by coaxing, with or without an hypnotic. Again, a case of paralysis of the foot, with talipes equino-varus, should be corrected by gradual means with plaster until it should be possible to perform the operation of tendon transplantation, or else an ankylosis of those joints which are likely to become unstable owing to the paralysis. Again, let us assume that the cxtensors of the wrist and fingers are paralysed. 
If there be no actual deformity, then a tendon transplantation can be performed. Forz example, the flexor carpi radialis and the flexor carpi ulnaris may be inserted into the extensors of the wrist and fingers, with an excellent functional result, provided the wrist:and fingers be kept from the end of the operation in complete extension in a plaster or Paris "cock-up" splint.

opponens paralysis, with marked disability of the thumb, especially for the finer $\frac{}{\bar{c}}$ movements with the little finger, can be treated with excellent results by a transposition $\overrightarrow{\%}$ of the flexor longus pollicis, as described by the author in the Lancet in 1926. Plastero of Paris is applied immediately after the operation to keep the thumb in the position of opposition.

(2) Arthritis.

Most if not all of the piteous deformities of polyarthritis can be prevented, by careful splintage, in the early stages of the disease.

Should, however, the orthopædic surgeon be called in only in the later stages of the disease, then he has many deformities to deal with, and these will tax his ingenuityo to the utmost. X-ray films should be taken of each joint prior to the treatment to determine whether it will retain movement or become fixed.

Plaster of Paris is the sheet anchor in the treatment of such deformities. This is applied with coaxing, caution, and with kindness, the deformities being corrected gradually. Since the patient's endurance has been sorely tried by the pain and disabilityy of the disease, great care must be taken not to exhaust her by doing too much at on ?

The length of time during which the plaster is kept on the affected limb depengiso first on the degree of deformity, secondly on the amount of pain, and thirdly on the $\mathrm{X}$-ray appearances.

Should the deformities be slight, the plaster remains on for a short time only Should the pain be intense and recur after the removal of the plaster, then it has to be renewed for an indefinite period of time. Should X-ray films show likelihood of ankylosis by bone, then the plaster is kept on until bony ankylosis is obtained. Hence the routine treatment of deformities due to polyarthritis is to apply plaster intermittently bivalving it from time to time accordingly to the above three indications. Once these. plasters have been made splints the masseuse re-educates the muscles to take on functiong once again. Should limited movement only be obtained, then a small metal or leatherio splint may be worn for a certain period of time during the day and left off at night Such leather splints are made from a plaster of Paris cast made from the deformed? limb.

Deformities of the Upper Limb.-The shoulder-joint should be kept in abduction in such a position that the hand can reach the mouth. This should remain on until alf pain has disappeared. The elbow if it be ankylosing should be kept at rest in plaster of Paris at $120^{\circ}$ in mid-pronation if the patient be a manual labourer; if, on the otherw hand, the patient be a clerk or a woman, ankylosis with plaster of Paris at $60^{\circ}$ to $70^{\circ}$ is more useful. The wrist should be slowly dorsiflexed until about $30^{\circ}$ have beenc obtained, due regard being paid to the position of opposition for the thumb.

The Lower Limb.-The hip should be ankylosed in plaster of Paris in deado extension, slight abduction and slight internal rotation.

The knee should be coaxed straight. If joint movement be possible, then the join $\frac{?}{0}$ 
should be allowed to flex daily, but replaced at night in the plaster of Paris splint. Should $\mathrm{X}$-ray films show the likelihood of ankylosis, then this should be obtained by keeping the plaster on until X-ray films show strong bony ankylosis. The ankle-joint should be dorsiflexed about $10^{\circ}$ with slight inversion. The toes should be coaxed straight and bunions treated surgically if necessary.

The trunk is often involved in this disease. Should the neck be stiff, painful and deformed, it can often be coaxed into a better functional position, with disappearance of the pain, and maintained thus with a plaster of Paris "collar." In a similar way kyphosis can be corrected by a plaster of Paris jacket or plaster of Paris bed.

\section{(3) Congenital.}

Club foot is one of the commoner types, and in the later stages of treatment by malleable iron splints, say after the sixth month, can be corrected by plaster of Paris. It is unwise, however, to apply plaster to the feet of children under the age of six months.

Torticollis, or wry neck, is often treated in plaster after tenotomy of the sternomastoid, the patient's head, neck and shoulders being incorporated in it.

Scoliosis.-Many cases of congenital and postural scoliosis, after being suspended or distracted, say by the Abbott frame, are kept corrected by plaster of Paris jackets. Later this deformity can be dealt with in the plaster bed at night, and a celluloid or preferably light steel support during the day.

\section{(1) Spinal Support.}

III.-Cásts.

Many a deformity of the back requires some form of metal support with a celluloid or leather fitting. Such cases are dealt with by the instrument maker, provided he has a plaster of Paris replica of the patient's deformity. This is obtained by plaster bandages applied to the oiled surface of the deformity, the plaster being bivalved when set. This is removed and filled up with plaster cream to form the replica. From this the instrument maker works out the detail of the spinal support.

(2) Limb Supports.

Certain deformities of the limbs require supports of leather or celluloid with steel incorporated in them. Such can be made to perfection with a plaster cast. Similarly, the bootmaker will supply boots for deformed feet. Again, certain amputation stumps can be fitted with a satisfactory artificial limb only if a cast be taken.

(3) Plaster Beds.

These are an essential part of the treatment of scoliosis, certain stages of tubercle of the spine and sacro-iliac joint, \&c., and are either made from a complete cast of the affected area, or from plaster strips placed longitudinally and transversely. This is then dried and fitted later with a wooden frame.

\section{(4) Permanent Records.}

This is perhaps one of the most important methods of recording, for use in museums, the rarer forms of deformity; also to demonstrate the various stages of a particular line of treatment, and to teach students and post-graduates the possibilities of orthopædic surgery. 
(I) Risk to Circulation.

\section{Abuse of Plaster of Paris.}

Risks are always present in every case under treatment by this method. There arecerlain definite contra-indications in its use; for example, should there be odemas following a fracture, it may be wiser to wait a few hours or days before its application In all cases the special cotton-wool and plaster of Paris bandages should be appliecte evenly and with no "pull."

Gangrene of the extremities may ensue twenty-four hours after the application ofo the plaster if this cardinal rule be ignored. The presence of a hæmatoma beneath thedeep fascia of the forearm may lead to Volkmann's ischæmic paralysis, especially if plaster be applied. Such a case may eventually arrive in the law courts, with damage to many professional reputations.

(2) Sepsis.

Plaster should seldom, if ever, be applied if sepsis be present. As the sepsis subsideso it may then be possible, but such cases are best referred at once to more senior $\vec{v}$ colleagues for guidance.

(3) Further Deformities.

Inexperience in the technique of the use of plaster of Paris may cause furthere deformity, especially if the limb be held by an assistant with little or no appreciation of the anatomical and functional details. For example, a Pott's fracture must be reducendeo completely, and then held in dorsiflexion and inversion whilst the plaster is appliegi, and kept absolutely in this position until the plaster has set. In fact the holder of tee limb has a responsibility greater than that of the surgeon who is putting on the plaster

(I) Bandages.

Technique of Plaster of Paris.

These should be of the best book muslin, No. I4 or I6 gauge. They should be효 cut into the required lengths and breadths, and the selvedge, etc., removed.

(2) Plaster.

The very best only should be used, called "Italian fine," and must be dry. Expert? rolling of the bandages is a sine qua non.

(3) Application of the Plaster.

Special non-absorbent cotton-wool bandages, or stockinette, are wound round the limb, which must be accurately held in position until the plaster has been applied and has set. The writer prefers to use hot water for ordinary work and cold water when making casts. Salt should not be added to the water since it makes the plaster see brittle. The date of the accident, the date of the operation, and the date of applicationviv of the plaster, together with an indication of the lines along which the plaster should be removed, should be clearly written on it in indelible pencil. When it is necessary tow split the plaster a scalpel or Stille's shears should be used.

The above description of the use and abuse of plaster of Paris has been writtenc with the endeavour to prove that much can be done by its means, but that to acquire? any skill in its application the surgeon must be prepared to serve a long and tedious apprenticeship, and unless he be willing to so serve it is dangerous for his patients anc damaging to his reputation. 